\title{
Contra-narrativas visuais e interseccionalidades entre raça e gênero na produção da artista Hariel Revignet
}

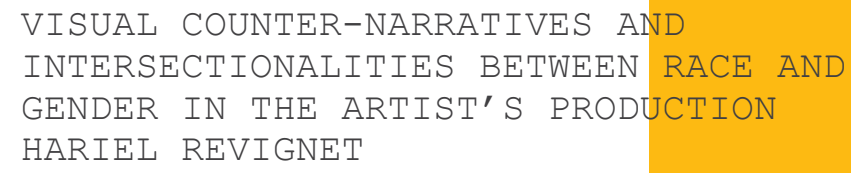

Nutyelly Cena de Olivera ${ }^{1}$

Hariel Chrystinne Oliveira Revignet ${ }^{2}$

\footnotetext{
${ }^{1}$ Museóloga, Arte-educadora, pesquisadora e curadora independente. Mestranda em Antropologia Social no Programa de Pós-Graduação da Universidade Federal de Goiás (PPGAS-UFG). Integra grupos de estudos e pesquisas como o Coletivo Rosa Parks e o NuPAA - Núcleo de Práticas Artísticas Autobiográficas. É articuladora no do Levante Nacional Trovoa.

Lattes: http://lattes.cnpq.br/6041243673181648.

E-mail: nutyellycenadoc@gmail.com.

ORCID ID: https://orcid.org/0000-0003-0906-1849

2 Arquitetura, pesquisadora e artista visual. Mestranda no Programa de PósGraduação em Arquitetura e Urbanismo da Universidade Federal da Bahia (UFBA). A artista é integrante do Levante Nacional Trovoa.

Lattes: http://lattes.cnpq.br/0550803555759962
} 


\title{
Resumo
}

No presente texto apresento um breve panorama das obras da artista Hariel Revignet (Gabão/ Goiás, 1996) em diálogo com conceitos utilizados pela artista. Interesso-me por abordar a sua produção em relação ao contexto contemporâneo em que se encontram a produção de artistas negros e negras, na presente Arte afro-brasileira. Tendo como reflexão uma prática socialmente engajada em que a artista constrói coletivamente entre vivências com mulheres negras e indígenas, como um fator essencial à sua existência e narrativas de si atreladas ao processo de pesquisa e criação.

\section{Palavras-chave}

Arte afro-brasileira; Hariel Revignet; Autobiogeografia; Decolonialidade

\begin{abstract}
In this text I present a brief overview of the works of the artist Hariel Revignet (Gabão / Goiás, 1996) in dialogue with concepts both used by the artist. I am interested in approaching his production in relation to the contemporary context in which the production of black and black artists is found, in the present Afro-Brazilian Art. Reflecting on a socially engaged practice in which the artist builds a collective practice between experiences with black and indigenous women, as an essential factor to her existence and narratives of herself linked to the research and creation process.
\end{abstract}

\section{Keywords}

Afro-Brazilian art; Hariel Revignet; Autobiogeography; Decoloniality

\section{Resumen}

En este texto presento una breve reseña de las obras del artista Hariel Revignet (Gabão / Goiás, 1996) en diálogo con conceptos ambos utilizados por el artista. Me interesa acercar su producción en relación al contexto contemporáneo en el que se encuentra la producción de artistas negros y negros, en el actual Arte Afrobrasileño. Reflexionando sobre una práctica socialmente comprometida en la que el artista construye una práctica colectiva entre experiencias con la mujer negra e indígena, como factor esencial de su existencia y narrativas de sí misma ligadas al proceso de investigación y creación.

\section{Palabras clave}

arte afrobrasileño; Hariel Revignet; Autobiogeografía; Decolonialidad 


\section{INTRODUÇÃO}

A escrita deste texto é um exercício de enunciação e interpelação. Para isso, buscamos tecer reflexões entre encontros, vivências, experiências, práticas e pesquisas no âmbito dos campos ${ }^{1}$ que nos permitimos vislumbrar. Tal exercício é impulsionado pela demanda da escrita como prática vivida. Como destaca Conceição Evaristo (2020) sobre as escrevivências e enunciações a partir da escrita de si. E como escrever sobre si e publicar é um ato político para nós mulheres negras, tornamo-nos autoras dos nossos próprios textos.

Nesse sentido, nos interessa experimentar a autoetnografia como possibilidade de agenciamento coletivo a partir das realidades e enunciações que vivenciamos. Nosso compromisso se dá ao repensar e reconstruir distinções de quem pensa e produz conhecimento no campo das artes visuais. Percebe-se, nessa experiência de escrevivência, uma tentativa de enunciarmos nossas experiências vividas que passam aos campos da curadoria e da prática artística por meio da linguagem escrita.

Neste texto, apresento brevemente alguns olhares da prática artística autobiográfica de Hariel Revignet. Estabeleço um diálogo com a artista para destacar alguns conceitos-chave que articulam o seu fazer e o seu pensar, propiciando uma reflexão mais profunda sobre traços sociais que permeiam os processos de criação da artista. Portanto, este texto apresenta posicionamentos pessoais e artísticos, possibilitando ao leitor que reconheça os potentes processos criativos como estratégias de resistência na luta antirracista.

\section{RASURAS NO CÂNONE}

Historicamente, o sistema da Arte tem subalternizado trajetórias e escolhido atentamente as artistas que são palatáveis ao cânone da arte ocidental. Com isso, compreendo ser fundamental olhar as produções de artistas negras no atual momento da arte contemporânea a partir dos debates decoloniais e da teoria feminista negra. Nesse sentido, é importante refletir sobre a possibilidade das práticas artísticas e curatoriais de maneira a constituir novas políticas do ver, oportunamente de forma conjunta ao sistema mercadológico das representações culturais e construindo novas imagens e imaginários sociais que, posteriormente, junto à linguagem, fornecerão as bases epistêmicas necessárias para a formação do sujeito protagonista.

Dessa forma, discutir a importância de uma nova narrativa para a historiografia das artes no que se refere ao confronto à colonialidade se torna fundamental para

\footnotetext{
$1 \quad$ Neste texto, enunciamos a partir da pesquisa, curadoria e das práticas artísticas auto-biogeográficas nas Artes visuais, Arquitetura e Antropologia. Em ambos, atuamos nas fissuras da colonialidade, da representação à emancipação. Assim como, neste texto, assumimos o uso dos termos: afro-brasileiros, afro-diaspóricos e artistas visuais negros e indígenas, para nos referirmos à produção artística realizada por pessoas negras e indígenas. Destacamos ainda, que a expressão Ameríndio aqui é referenciada nas primeiras escritas da artista, porém, como pesquisadoras partimos de processos de amadurecimento e aprendizagens contínuos, achamos importante frisar a análise feita pela Dra. Julie Dorrico, ativista indígena sobre o uso desta expressão ameríndia, que evidencia a presença silenciada e invisibilizada dos povos indígenas, e esta, aponta para o processo colonial de tratar os povos originários a partir do nome do colonizador "Américo".
} 
a construção de contradiscursos e estratégias para a afirmação da presença de indivíduos e o reconhecimento histórico cultural negra e indígena.

O campo das artes visuais contemporâneas, bem como os museus e as exposições culturais passam atualmente por um processo de transformação e incorporação. Apesar da complexidade desses termos, é possível perceber uma notável tentativa de articulação e interesses por narrativas que foram historicamente desvalorizadas e silenciadas em detrimento de uma branquidade, relações de poder e uma elite estabelecida.

De um lado, é possível encontrarmos uma diversidade e recepção de debates relacionados às questões étnico-raciais e de gênero em museus, galerias e projetos independentes. Entretanto, apesar da insurgência de debates realizados por artistas e curadores/as negros/as e indígenas frente às estruturas de dominação, ainda se perpetuam marcas de um colonialismo cotidiano. São constantes as tentativas das instituições em dialogar com os efeitos da discriminação racial na sociedade brasileira, porém ainda são poucas as estratégias construídas pelas mesmas para superar as dificuldades dos problemas estruturais, como a entrada e permanência de corpos negros e indígenas em posições e instâncias decisórias de produção de narrativas.

Por mais que pautas como essas estejam sendo levantadas pelas instituições, o racismo ainda prevalece em suas estruturas. Grada Kilomba (2010) faz uma reflexão sobre os lugares contemporâneos da fala de indivíduos que historicamente encontramse numa condição subalternizada. Para isso, a autora levanta as seguintes questões sobre esse lugar de enunciação: "quem pode falar? quem não pode? e, acima de tudo, sobre o que podemos falar? o que acontece quando falamos? " (KILOMBA, 2010 , p. 33). Neste sentido, quando a autora coloca essas questões podemos pensar nos museus enquanto espaços de falas e na forma como e por quem são estruturadas as agendas oficiais de debates e exposições.

Mesmo que experiências tenham sido criadas por pessoas negras, abordando direitos e visibilização de questões étnico raciais nas instituições artísticas, tratase também de estabelecer estratégias políticas de ocupação de espaços de falas significantes

Considero as práticas artísticas e curatoriais adotadas por artistas e curadoras negras insurgentes e transgressoras, pois nos instrumentalizam para lidar com processos violentos e excludentes criando, assim, outras rasuras e geografias que se convertem em diálogos, curam e criam espaços de agenciamento. Essas estratégias são uma crítica à imagem eurocêntrica (SHOHAT; STAM, 2006) e permitem ressaltar aspectos que não foram criticados por uma historiografia oficial que ditou a construção de imaginários sobre a nossa história.

Essa é uma das estratégias que se encontra para afirmar um espaço de fala e escuta aos considerados subalternos pela lógica dominante. Isso significa também um fomento às estratégias que afirmam a cultura e a arte como fonte de um reparo necessário e justo à parcela da população historicamente invisibilizada e explorada por uma salvaguarda e memória de uma nação brasileira que reconhece o mito da democracia racial. 
O pensamento intelectual da afro-americana bell hooks (1992; 2013) apresenta uma importante contribuição, pois não se trata de uma autora que ora escreve sobre teoria feminista e ora escreve sobre crítica cultural, mas de uma mulher negra engajada em uma crítica anticapitalista, que busca, a partir do exercício da consciência crítica, construir um novo imaginário político e social para comunidade negra, sobretudo afro-diaspórica. bell hooks (1992) evidencia que na dimensão das representações culturais e dos regimes imagéticos de imagens de controle, podemos compreender essas etapas em um processo de constituições de conceitos que são mediados pela linguagem.

As representações culturais informam os processos de sujeição contemporâneos mediados pela linguagem e pelos regimes normativos imagéticos da supremacia branca constituindo o que bell hooks chama de margem. E para a produção de representações positivas é preciso "transformar as imagens, criar alternativas, questionar quais tipos de imagens subverter, apresentar alternativas críticas e abrir espaço para imagens transgressoras" (HOOKS, 1992).

O pensamento da autora nos indica de forma precisa maneiras de construir práticas revolucionárias de resistência, advinda da necessidade de construção de novos espaços de agência para pessoas negras, onde possamos ao mesmo tempo opor o olhar do Outro colonizador como também afirmar uma agência ao reivindicar esse "olhar" e "consciência" ao reaprender novas formas de resistência partidas desse olhar (HOOKS, 2019, p. 217).

Ao desvelarmos a história das artes visuais, bem como ao estudarmos as histórias das humanidades, ainda são incômodas as imagens que são subalternizantes das populações negras e indígenas. Como transcender às vistas dos públicos? Como tratar da construção desse imaginário de modo a ressaltar a violência e arbitrariedade do processo de colonização e, ao mesmo tempo, ativar a agência, e existência da insurgência das populações negras e indígenas em todos os períodos?

No contexto das exposições artísticas, havia a busca pelo exótico e para a construção de uma identidade nacional. A partir de uma análise decolonial e antirracista se percebe que muitas delas, por sua vez, perpassam por processos de visualidades que processos de traumáticos, reforçando estereótipos.

As imagens produzidas e que emergem de corpos, territórios e identidades que foram forjadas tensionam as narrativas históricas causando fissuras, muitas vezes construídas criticamente. Por isso, o foco deste texto é pôr em evidência o atual surgimento da autorrepresentação em práticas artísticas e a construção de contranarrativas por parte das curadorias, que se tornam instrumentos de reparação e recusa da imagem estereotipada de corpos, suturando com a transgressão o olhar colonizador.

As práticas artísticas e curatoriais, principalmente no Centro-oeste, Norte e Nordeste, trazem contribuições para pensarmos primeiramente em questões geopolíticas que tanto contribuem para a manutenção de um epistemicídio (CARNEIRO, 2005). Tais produções estão trazendo outras roupagens para o cenário das artes e museus, muitas vezes questionando e criticando as imagens de controle, 
dominação e exotização ainda presentes no imaginário coletivo (COLLINS, 2019). São práticas interessadas em reivindicações de autoridade (KILOMBA, 2019), nas quais a prática artística permite que alteridades emerjam. Por essa razão, nessa desobediência estética afro-orientada encontramos artistes contemporâneas e curadoras que constroem em suas práticas a transgressão (HOOKS, 2013), onde compreendem outras estratégias e ressignificações de olhares que nos tiram do lugar comum, questionando a hegemonia e nos propondo a reconstruções do imaginário ressignificando práticas e conceitos para a subversão da heteronormatividade.

As redefinições do contexto das visualidades são acompanhadas com as identidades negras, movimentos negros e indígenas e modificações que refletem na sociedade, como detentores de um conhecimento, autoidentificação e autoconsciência. As práticas lidam com questões étnico-raciais, questionando e rediscutindo os fazeres na arte afro-brasileira. A inserção da desobediência estética afroorientada apresentam um contra-olhar à hegemonia de um modo de fazer e representar o outro. Nesse sentido, produções artísticas que demostram uma desobediência estética que passaram despercebidas por séculos ou décadas por ocorrerem de forma sutil (SIMÕES,2018. 2019).

\section{A EXPERIÊNCIA DO CORPO COMO MARCADOR: HARIEL REVIGNET}

A autoridade de narrar a própria história permite ao sujeito o direito de definir sua própria realidade, estabelecer suas próprias identidades e nomear suas próprias histórias. Como objeto, sua realidade é definida por outros, sua identidade é criada por outros e sua história é somente nomeada de maneiras que definem sua relação com aqueles que são sujeitos (HOOKS, 2019). Esse mecanismo de sujeição, dentro da dialética de subordinação, cria contradições na qual o subordinado terá sua subjetividade moldada a partir da subjetividade do outro. A voz estabelece entre o objeto e sujeito - da autodefinição, um mecanismo da autoconsciência que não vai ser moldada a partir da consciência de outro sujeito. Nas dinâmicas do pensamento feminista negro, a postura de assumir posicionamentos políticos, ideológicos e o ato de erguer a voz a partir da sua experiência, de maneira a assumir-se enquanto sujeito da própria narrativa (GONZALEZ,1988; HOOKS, 2019).

Hariel Revignet (Goiânia - 1995) é brasileira-gabonesa, graduada em Arquitetura e Urbanismo pela Universidade Federal de Goiás (UFG), mestranda no programa de Pós-Graduação em Arquitetura e Urbanismo da Universidade Federal da Bahia (UFBA), artista visual e performer (Figura 1). A artista é integrante do Levante Nacional Trovoa, uma articulação nacional de artistas visuais, arte-educadoras e curadoras racializadas pertencentes das cinco regiões brasileiras.

A produção da artista contemporânea está pautada nas referências de artistas visuais negros e indígenas contemporâneos como Rosana Paulino (São Paulo), Renata Felinto (Ceará), Uyra Sodoma (Amazonas), Kerolayne Kemblin (Amazonas) e Tassila 
Custodes (Maranhão).

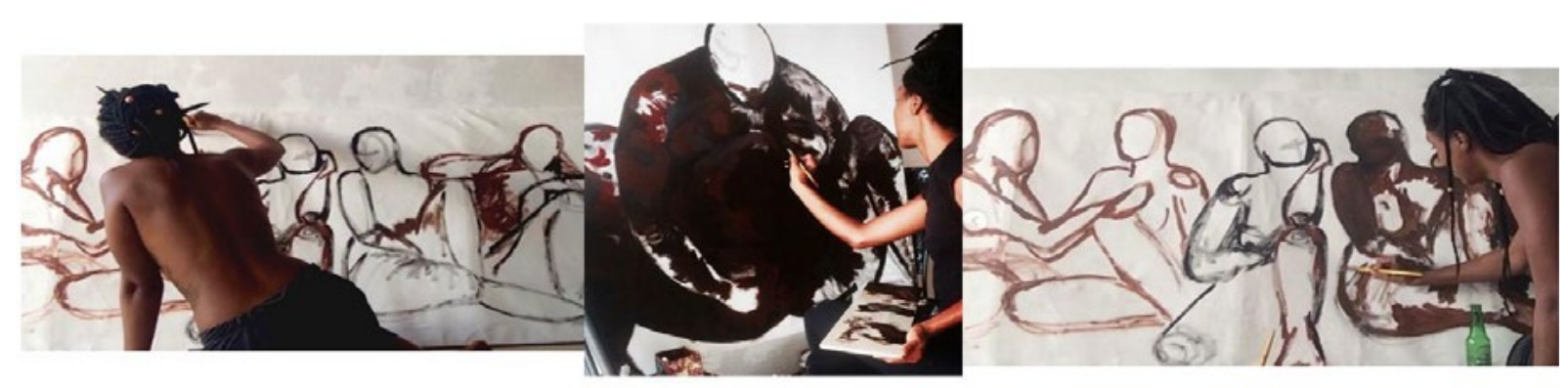

Figura 1: Hariel Revignet, Autorretrato, 2019. Fotografia. Fonte: Acervo pessoal da artista

A artista realiza pesquisas artísticas autobiogeográficas a partir do feminismo negro com o foco decolonial afro-diaspórico. Criadora do conceito poético Axétetura, cunhado durante seus estudos na graduação em arquitetura e urbanismo, Hariel tensiona o papel da hegemonia frente ao racismo estrutural. Sua produção artística se apresenta nas poéticas que perpassam as narrativas de si e sua prática instaura atos de confronto aos traços persistentes da colonização em corpos pretos e indígenas. Essa prática realizada pela artista e por muitos outros, possibilita uma decolonização do olhar do outro, pautado em equívocos e estereótipos, para a transgressão do silenciamento velado a luta pelo debate afro-diaspórico e as contribuições dos povos indígenas

\section{AGOMBENERO}

Em seu processo criativo, Hariel define a pintura-instalação como uma marca presente na sua produção, pois usa elementos como búzios, palha da costa, galhos e cipós de árvores, que saltam para fora da tela, como se os corpos astrais-ancestraisvivos retratados precisassem circular entre nós. Em uma entrevista para a Galeria Kura por Thais Teotónio², a artista fala sobre como vê a tradição da pintura e como a sua ancestralidade atua de forma atravessada em seus processos com a pintura contemporânea, sobre a qual afirma:

A construção de narrativas a partir da imagem é um elemento poderoso de criação de imaginário coletivo, vejo a pintura assim como a fotografia e outras linguagens artísticas na disputa de contra-narrativas, possibilitando revisitar ideias coloniais ocidentais que distanciam a pintura de uma apropriação coletiva sem hierarquia. Representação de símbolos, corpos e suas sinergias ativam a memória coletiva, no entanto as imagens podem ser feitas para gerar esquecimento ou recorte histórico, em que só uma narrativa hegemônica é reconhecida como "oficial" e "clássica". Decolonizo minhas referências de 
clássico entendendo como sempre atuamos através de diversas tecnologias de representação dentro da pintura. Ancestralidade vai além do tempoespaço linear, assim minha ancestralidade é contemporânea. Ela existiu e re-existe no agora assim como no porvir. (REVIGNET, 2020, p. on-line, grifo meu).

A artista defende o fato de as populações negras e indígenas serem, em suas obras, sujeitas a si mesmas. Em suas pinturas-instalação, Hariel aborda temas e trajetórias com um olhar atento às questões que vão desde identidades ao enfrentamento da invisibilidade histórica contra as populações colocadas estruturalmente à margem da sociedade. Ao utilizar traços fortes, paleta na cor marrom escuro e bem demarcada na cor da pele dos sujeitos de sua pintura, a artista se posiciona contra a representação estereotipada e o embranquecimento (SOUZA, 1983; MUNANGA, 1999) da população negra nas produções artísticas e na sociedade brasileira. Com o intuito de provocar uma discussão, a artista demarca na pintura de corpos negros como sendo um processo em coletividades

Quando pinto mulheres afro-diaspóricas e ameríndias, o tempo é atravessado pelas ancestrais do passado e do futuro. Como minhas práticas são autobiogeográficas, pintura-vivências-performance e ritualística faz parte do meu cotidiano e das mulheres que convivem comigo. Dentro do terreiro, na comunidade, nos movimentos sociais. (REVIGNET, 2020, on-line, grifo meu).

O antropólogo congolês Kabengele Munanga (1999), em Rediscutindo a mestiçagem no Brasil: identidade nacional versus identidade negra, traz um debate importante acerca do processo de branqueamento como uma estratégia violenta do processo de mestiçagem no Brasil, demonstrando que essas tentativas auxiliaram na configuração de uma "democracia racial" (MUNANGA, 1999, p. 10). Frente a essas violências estruturais e em decorrência da aniquilação e do embranquecimento da população negra, a autora negra Nilma Lino Gomes nomeia esse processo como morte identitária (GOMES, 2003). Assim, entendemos que o processo de embranquecimento constituiu-se com finalidade de alcançar o branqueamento físico - incluindo cor de pele, traços físicos e outros fenótipos - dos/as afrodescendentes brasileiros/as. Portanto, o trabalho de Hariel Revignet se configura, também, como estratégia de resistência, no qual a pesquisa, conteúdo e forma se articulam e caminham lado a lado. 


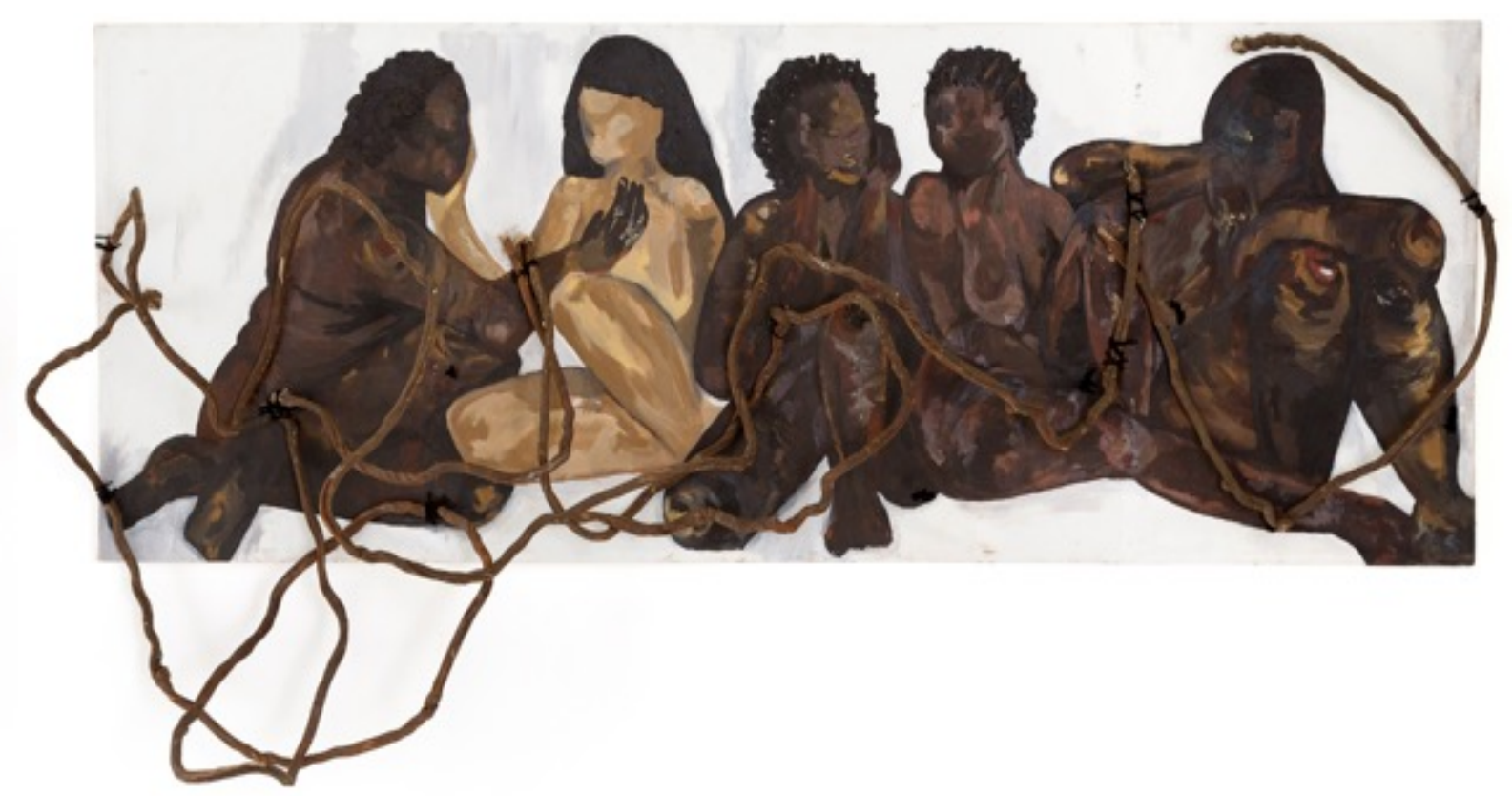

Figura 2: Hariel Revignet, Agambonero, 2018. Técnica, dimensões 1,10 x 2,30. Fonte. Registro fotográfico feito pela artista

Na exposição Um corpo no ar pronto para fazer barulho (2019), realizada entre dezembro de 2018 e março de 2019 no Museu de Arte de Contemporânea de Goiás (MAC-GO) ${ }^{3}$, com curadoria de Raphael Fonseca, uma obra de grandes proporções introduziu a produção artística e os temas ali questionados. A obra que deu o tom da mostra ao público foi o trabalho Agambonero Ancestrais (2018) (Figura 2).

A obra Agambonero - Ancestrais (2018) é um trabalho artístico que surgiu como um dos resultados de uma residência e imersão artística e curatorial intitulada Trampolim: mergulho para novos artistas que aconteceu em Goiânia no período 20182019. Esta residência foi para a artista uma tomada de consciência de sua prática artística, tanto que o desenvolvimento desta produção pode ser lido a partir das reflexões feitas por bell hooks (2010) em Vivendo de Amor sobre a experiência do afeto como um processo e ação prática de cura entre os corpos negros.

Nesta composição, Hariel Revignet trabalha com a pintura-instalação com o objetivo de construir tempos-espaço para ativar curas em corpos colocados historicamente à margem. A pesquisa ancestral (e espiritual) começa na própria árvore genealógica da artista, focando nos laços a partir de uma linhagem matriarcal. O resultado é o encontro de suas origens, a africana e a indígena. Ao pedir licença para a construção de imagens rizomáticas, conceito definido pela artista como um diálogo com a natureza, Hariel nos conta sobre a presença das raízes de árvores em seu processo de apropriação e criação nas pinturas:

É reivindicando uma herança escolhida-axétetura- como processo de

3 O MAC-GO integra o complexo do Centro Cultural Oscar Niemeyer (CCON). Website: https://www. facebook.com/mac.gomuseu/ 
produção espacial coletiva em negociação com a memória seletiva, que crio imagens rizomáticas pintadas costuradas amarradas queimadas para desmaterializar o tempo, evocar o invisível. Intento experiência sinestésica, diluindo aos poucos a predominância da visão. Apesar de construir imagens, a pretensão é com isso apropriar do espaço a partir dos outros sentidos. Pintura que pede outras posturas corporais, diferentes formas de contato. A criação de um imaginário coletivo ancestro-futurístico cria espaços para as dívidas serem pagas. (REVIGNET, 2021, on-line, grifo meu).

A percepção de distanciamentos e conexões transformou a própria elaboração do trabalho em processo de cura. Além disso, o desenvolvimento deste primeiro trabalho possibilitou a abertura de importantes encruzilhadas para si e caminhos abertos à artista que emergem do reconhecimento de sua produção frente ao cenário contemporâneo das artes visuais brasileiras

Expor Agombenero I Ancestrais é resultado de grande mergulho interno. Queria falar da minha linhagem matriarcal, africana, afro-brasileira e ameríndia. Sobre esse encontro diaspórico, cicatrizes coloniais e dores do passado, do presente. Mas nesse mergulho minhas ancestrais, entidades das águas, seres das matas, sons do vento, fogueiras dançantes me falaram muito mais de união, de cura, dos ciclos da natureza e perdão. Minhas ancestrais (re)existem em mim, e se sou fruto dessa grande árvore, minha essência é a delas, amor puro. E eu que queria fogo na casa grande entendi que gastei muita energia pensando no outro lado. Nesse mergulho com a ancestralidade da floresta me mostrou que se eu me encho de ódio, eles venceram. Porque o ódio, o ego, a destruição, a covardia é coisa deles. Essa onda de ódio que adoece, aliena, corrói. Eles não vão me contaminar, vou permanecer com minha essência e continuar a ser AMOR apesar deles. Não importa o que façam, digam, ou matem. Somos amor. Aqui e no astral. Amando honro aos meus e tudo que digo, penso e faço é revolução. Como diz Conceição Evaristo, não é pra ninar a casa grande e sim para incomodá-los em seus sonos injustos. (REVIGNET, 2018, on-line). 

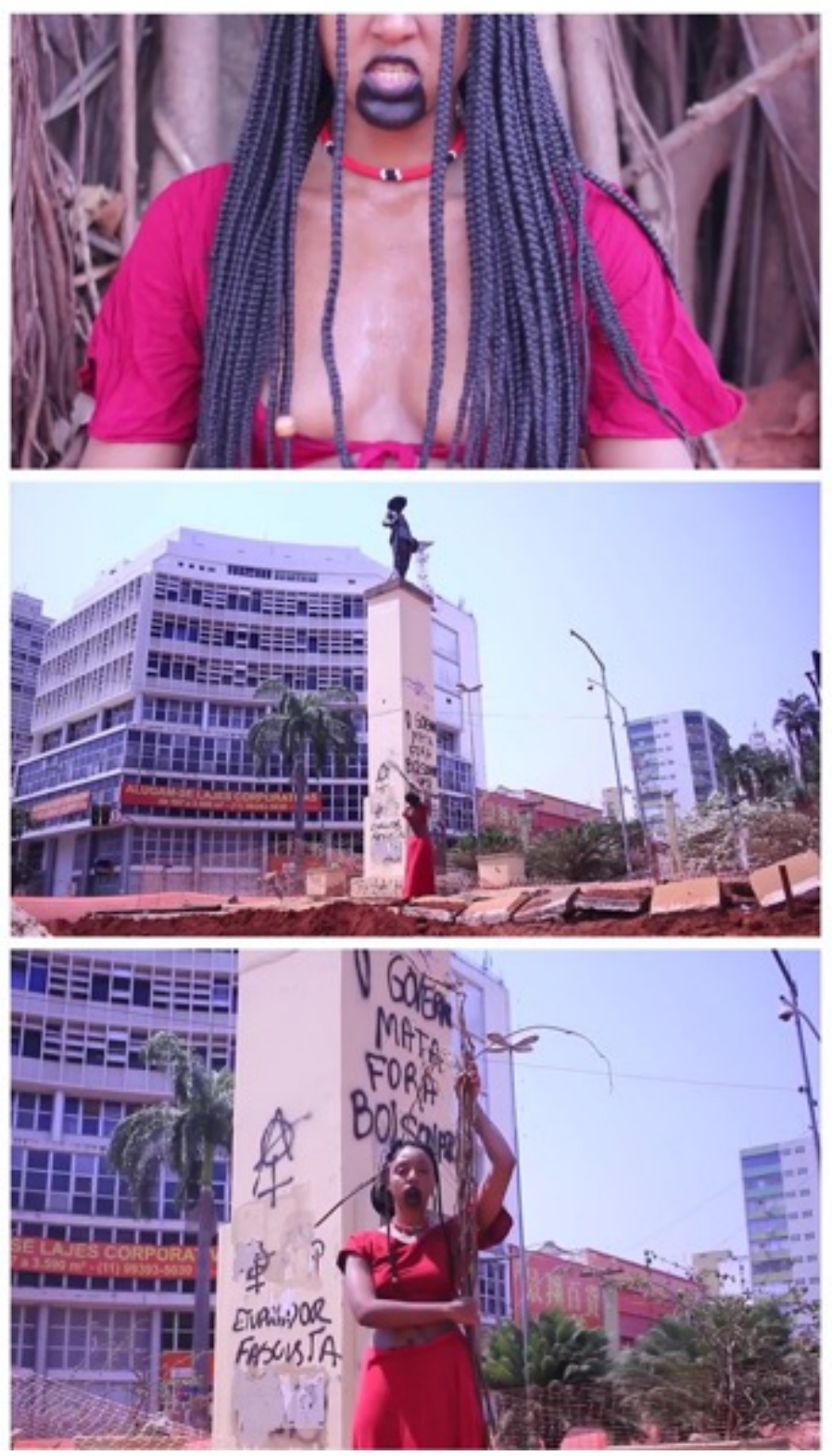

Figura 3 - Hariel Revignet e Mirna Anaquiri., AMARRAÇÃO, 2020. Fotografia. Créditos: Filmagem, som e montagem lago Araújo e música de Karl Araújo. Fonte: Acervo pessoal da artista

A artista também define sua prática com a linguagem da performance-vídeo como poesias-visuais, pois seu processo requer pesquisa, escrita poética, desenhos, esboços e a captura de imagens geradoras de discursos. Segundo Hariel, há nesses processos uma responsabilidade de se construir gestos, ações e imagens, pois ativam memórias que são demarcadas no inconsciente coletivo dos territórios de povos originários que esfarelam as fronteiras coloniais.

A videoperformance Amarração (Figura 4) foi realizada em uma das principais avenidas da cidade de Goiânia-Goiás, na avenida Anhanguera, cujo nome da avenida e o monumento que se localiza nela, se deve à Bartolomeu Bueno da Silva (filho) conhecido como Anhanguera, nome que significa Diabo Velho por ter assassinado muitos indígenas da região. Hariel escolhe chicoteá-lo devido a sua crueldade e 
caráter genocida para com os povos indígenas. Neste trecho é possível compreender a produção de Hariel, por sua vez, como um trabalho que adveio de situações vivenciadas por populações, indígenas e negras no Centro-Oeste, neste contexto, no que tange aos processos de construção de identidade goiana em intersecção com a raça e o gênero. Sobre qual a artista afirma:

Vim para dançar a lembrança. Vim para amarrar. nessa dança que é jongo capoeira e marcação de trincheira porque vamos lançar o raio. Vamos desatar seu pacto. seu discurso não te protege. sua ladainha não te protege. sua tecnologia não te protege. você não é meu inimigo. você é só um pobre bandido. bandido bom não é bandido morto. Bandido bom é aquele que devolve o que roubou. se você é o tipo de ladrãozinho por herança e quer parar com a sua sociopatia ancestral coletiva, cê deve dobrado. Fique calado na casa alheia, devolva tudo. Não você não é aliado nessa luta, você é devedor. (REVIGNET, 2020, on-line)

A vídeoperformance faz parte do processo de produção das obras Abandji (Figura 5) e Maracanandê, ambas foram realizadas "evocando nossa responsabilidade com a manutenção da vida e a licença aos donos da casa, os povos indígenas e ameríndios" (REVIGNET, 2020, on-line.). São importantes a memória e os processos de construção identitários de distintos segmentos, no centro-oeste de Goiás, como os afro-brasileiros, indígenas, quilombolas, afroindígenas, ciganos, dentre outros grupos.

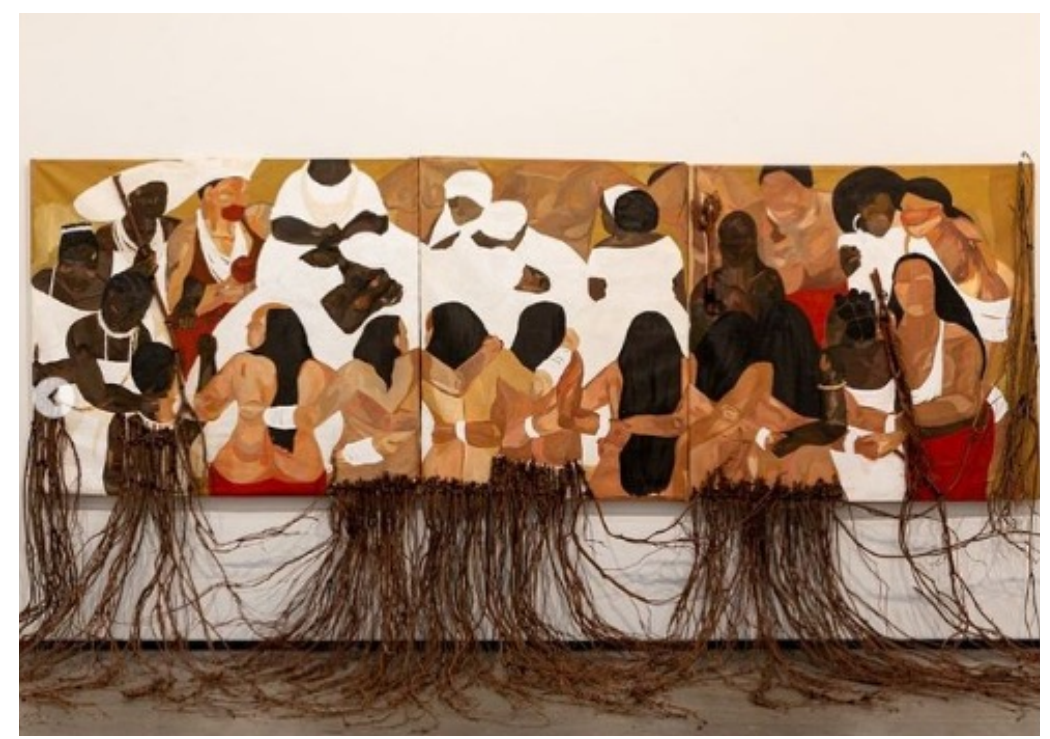

Figura 4: Hariel Revignet, "Abandji - Tríptico", 2020. Pintura acrílica, tinta pva, verniz, costura com lã preta de cipós de árvore Figueira - Gameleira. Fonte: Acervo pessoal da artista

Na série de trabalhos Aningo Mezanga I-IIII (Figura 5) Hariel apresenta pinturas de sonhos e a realidade, entre o físico e o onírico. Este trabalho investiga suas 
experiências de lutas e articulações com as pautas históricas das mulheres negras e indígenas. A pinturas são "impulsionadas pelo sentimento de encontro e cura perante ao despertar onírico mergulhado em minhas águas profundas que desaguam em poesias visuais" (REVIGNET, 2020).
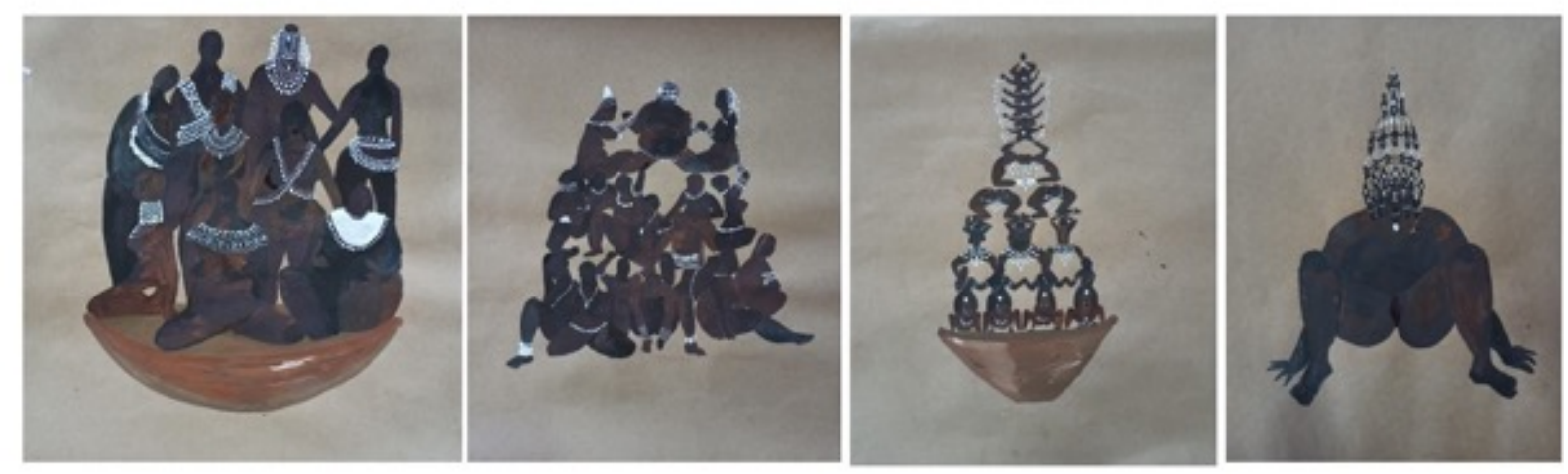

Figura 5: Hariel Revignet, 2020. Aningo Mezanga I-IIII, Pintura acrílica em papel craft. Fonte: Acervo pessoal da artista

Com a intenção de compreender as noções de narrativas afro-diaspóricas, identidades e interseccionalidades entre raça e gênero presentes na produção da artista, alguns conceitos se tornam fundamentais e nos aproximam de suas pesquisas e subjetividades, como a noção de autobiogeografia (RODRIGUES,2017), que se constituem como um modo de prática artística em meio das narrativas de si, memórias e histórias de vida. De acordo com Manoela Afonso Rodrigues (2017), a autobiogeografia consiste em uma "metodologia crítica, situada, e criativa, capaz de articular práticas decoloniais" (RODRIGUES, 2017, p. 3155). Sendo assim, as narrativas autobiogeográficas contidas nas produções da artista, tornam-se reveladoras das subjetividades de si, enquanto mulher negra em diáspora, referentes ao seu corpo negro coletivo, à sua autobiografia, à sua constituição identitária familiar, experiências vividas com mulheres quilombolas e indígenas dentro de uma sociedade patriarcal e excludente.

É importante ressaltar a opção da artista em colocar sua pesquisa artística embasada na perspectiva decolonial e autobiogeográfica. Sendo assim, contribui no processo de uma desobediência epistêmica e política na arte, que perpassa, inicialmente, as proposições defendidas pelo peruano Aníbal Quijano, e suas discussões sobre colonialidade do poder. Consequentemente, a artista apresenta essa desobediência ao narrar as suas histórias de vida tecidas individualmente e em coletividade em meio aos processos de luta de negras, negros e povos indígenas,

Os campos dos estudos decoloniais têm contribuído para a formulação de um pensamento crítico e situado na América Latina. Entretanto, existem contradições e disputas de conceitos, narrativas e abordagens com distinções epistêmicas, como decolonial, descolonial, pós-colonial e anticolonial, que marcam a importância desses 
estudos para a construção de perspectivas críticas e de resistências a partir do Sul Global, América Latina ou em Abya Yala.

O discurso hegemônico historicamente construído em forma de dominação é amplamente criticado a partir dos processos que contestam a forma como a história é retratada, ou seja, a partir de um único continente referencial. No âmbito desses estudos, algumas abordagens partem do argumento de que os efeitos da colonização deixaram marcas em três dimensões principais: o saber, o ser e o poder (QUIJANO, 2005). A pós-colonialidade e a decolonialidade partem da crítica da produção de conhecimento centrada na Europa, desvinculando o sujeito da produção, sendo arquitetado um conhecimento tomado como universal e neutro (BALLESTRIN, 2013).

No entanto, é de se valorizar o esforço de intelectuais e artistas indígenas brasileiros contemporâneos em situar suas experiências de enfrentamentos e críticas ao colonialismo (KRENAK, 2019; MUNDURUKU, 2012; POTIGUARA, 2018; GUAJAJARA, 2018; ANAQUIRI, 2017; KOPENAWA e ALBERT, 2015; ESBELL, 2013). Tais pensadores nos auxiliam a formular um pensamento crítico baseado em epistemologias políticas que tanto contribuem para possiblidades de novas reflexões, ações e práticas.

Da mesma forma, também é importante ressaltar reflexões e caminhos dos debates engendrados por pensadores/as negros/as no que diz respeito aos debates sobre a decolonialidade. Elementos importantes para pensarmos nas experiências de pessoas negras nas práticas artísticas são apontados pela intelectual Renata Felinto dos Santos $^{4}$ em sua participação conjunta com o curador e professor lgor Simões na mesa Saberes e Práticas Artísticas Decoloniais, da Associação Brasileira de Críticos de Arte (ABCA), no ano de 2020. Essa edição online teve como tema "Resistências poéticas: arte, crítica e direitos humanos".

A questão colonial está em discussão entre pensadores africanos e das lutas da população indiana, e o decolonial tem sido uma palavra que busca conceituar a análise crítica sobre o pós-colonialismo. Ao tratar de estudos pós-coloniais na Améfrica Ladina (GONZALEZ, 1980), ou na Abya Yala, Renata Felinto (2020) reflete sobre os saberes e fazeres de intelectuais negros, bem como sobre suas contribuições importantes para pensarmos nas matrizes coloniais de dominação que se atualizam constantemente. Segundo ela:

Por que os intelectuais negros e negras do Brasil não foram e não são levados em consideração em vida? Por que precisam morrer para que suas ideias vivam na intelectualidade? E como não hierarquizar os conhecimentos produzidos por cabeças brancas e pretas? Visto que diversos/as intelectuais negros/as não foram lidos/as ou escutados/as. Será que essa é a profunda marca sangrenta da colonialidade na academia brasileira? Porque é aqui que fazemos esses ajustes (SANTOS, 2020, p. 51).

Ao apontar uma crítica à forma como os pensadores negros não tiveram suas

4 Associação Brasileira de Críticos de Arte (ABCA) com a artista e professora Renata Felinto dos Santos, 2020. Disponível em < https://www.youtube.com/watch?v=ag4Ci2tkO3c > Acesso em 15 de fevereiro de 2021. 
contribuições e reflexões valorizadas em vida, tal como as proposições da branquitude informada da América Latina ou do Brasil, Felinto (2020) também chama atenção para a maneira pela qual o pensamento decolonial foi sendo organizado no campo da academia brasileira e nas artes visuais. Os intelectuais negros antecedem, no Brasil, os debates decoloniais, ainda que estejam sendo resgatados nos debates contemporâneos de hoje, tanto no campo das Artes quanto de forma lenta em outros campos, "por que o pensamento decolonial se orienta no Brasil pelo 'despertar' da branquitude informada?" (SANTOS, 2020, p. 47). Antes dessa branquitude informada da América Latina já tinham pessoas pensando decolonialidade, só não usavam essa palavra, e temos "investidas decolonias, afroorientadas nas artes visuais antes do 'decolonial'" (SANTOS, 2020, p. 47).

Renata Felinto nos convida a dialogar sobre as contribuições ao pensamento decolonial a partir da contribuição do pensamento de intelectuais negros e negras no Brasil que já acenavam para o viés crítico. Porém, não foram valorizados. Entre eles e elas estão a antropóloga Lélia González, a Rainha estrategista Nzinga Mbandi, os líderes Gamga Zumba e Zumbi, o intelectual Manuel Raimundo Querino, o sociólogo e político Alberto Guerreiro Ramos, a socióloga e psicanalista Virgínia Leone Bicudo, o intelectual, professor e artista Abdias Nascimento e Maria Beatriz Nascimento entre outros.

Para tanto, a autora nos propõe pensar a partir da Confederação do Quilombo dos Palmares (1605) como marco decolonial brasileiro, pois já se organizavam e anunciavam respostas ao projeto colonial português, frente a ambas possibilidades de formulação de uma alternativa de sobrevivência e defesa à sociedade escravista baseada da exploração física e violenta do corpo da pessoa negra como instrumento do projeto colonial (NASCIMENTO,1985; SANTOS, 2020).

Entre outros pensadores destacados pela intelectual, podemos mencionar Sojourner Truth (1797-1883), W.E..B Du Bois (1868-1920), o Movimento Negritude e tantos outros intelectuais afro-diaspóricos que já estavam forjando outras formas de ser e de estar na cultura brancocêntrica (DU BOIS, 1998; GILROY, 2012; SANTOS, 2020).

A abordagens desses intelectuais não resgatam, mas evidenciam e reivindicam outras formas de ser e estar no mundo com narrativas positivas, mesmo que toda a herança colonial não os tenha evidenciado, ao ponto de terem que negociar com uma intelectualidade branca que dominava, e ainda domina as regras e, de certa maneira, não garantem abertura para que se realize uma reflexão pautada contra a colonialidade. Entretanto, as insurgências epistemológicas e decoloniais de intelectuais negros, apontam para a quebra do epistemicídio (CARNEIRO, 2005), da invisibilidade e exclusão reproduzida pelas estruturas históricas da colonialidade. E é preciso evidenciar que descolonização só será possível em coletividades, pois não há a construção de pensamento e práticas decoloniais se não incorporarem intelectuais que antecedem, ou seja, o pensamento de povos negros, indígenas dentre outros subalternizados pela colonialidade.

Convém ressaltar a necessidade de discutir temas tão importantes presentes na 
trajetória pessoal e nas obras de mulheres artistas afro-brasileiras. Assim, a resistência nas práticas artísticas, das diferentes maneiras de ver e de interpretar o mundo, perpetuada por intelectuais e artistas visuais negros e indígenas, é incorporada nas obras da artista que expõe a constante luta dos seus povos contra o colonialismo atualizado.

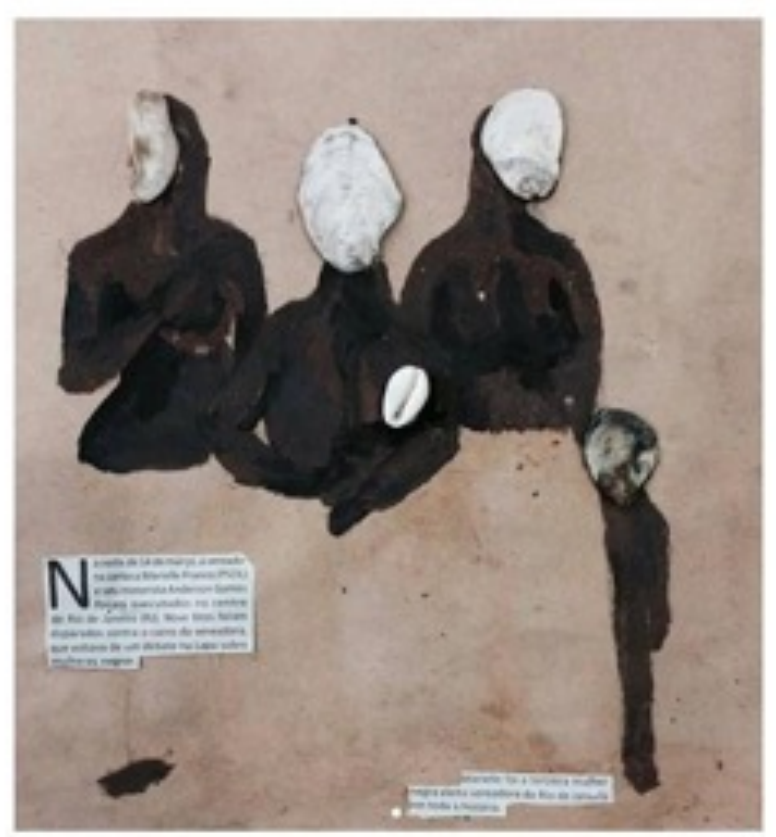

Figura 6: Hariel Revignet, Por cima do mar eu vim, 2019. Pintura acrílica e colagem de conchas e recorte de revista. Fonte: Acervo pessoal da artista

O processo da produção da obra Por cima do mar eu vim (Figura 5) de Hariel, se deu a partir de uma série de colagens que tiveram como intuito aproximar a teoria estética da arquitetura e da arte com novas visualidades e práticas decoloniais, evidenciando mulheres negras enquanto referências simbólicas de uma tomada de poder. Nesta série, Hariel faz uma referência a Marielle Franco, como Nzinga Mbandi, símbolo de resistência ao colonialismo português e uma importante líder política africana e rainha de Congo. Percebo isso de forma muito sensível, visto que vivemos em um país construído sobre bases racistas, onde uma mulher negra no poder é uma ameaça e também sua cor da pele como fator determinante nas estruturas das relações de poder e privilégios são estabelecidos socialmente. $O$ lugar que a artista ocupa, enquanto mulher negra no contexto das artes visuais, faz com que se atente às representações artísticas no sistema de arte contemporâneo a respeito do protagonismo de mulheres negras e indígenas.

Lembremos o dia 14 de março de 2018 o caso de assassinato da vereadora Marielle Franco, mulher negra e de periferia que foi morta brutalmente com três tiros na cabeça e um no pescoço, assim como o motorista do veículo em que a vereadora se encontrava, Anderson Pedro Mathias Gomes, que também foi assassinado. Essa 
tentativa de silenciamento de uma voz que já não demonstrava ceder, pelo lugar que ela ocupava, Marielle ao difundir suas ações e reivindicações em prol do coletivo, imaginávamos que não poderiam calá-la. Estávamos esperançosos e com um forte desejo de mudança e a vontade de continuar sempre em luta junto com Marielle Franco.

Após as mortes de Marielle e Anderson, tivemos mobilizações mundiais, manifestações, marchas e gritos por justiça aos corpos negros e todas as violências que nos assolam. Nos encontramos desamparados, com lágrimas nos olhos, com sentimento de impotência e amedrontados por uma estrutura de poder racista que por consequência não se alinham a uma consciência dos problemas sociais, raciais, de gênero e de diversidade sexual.

Compreendemos o desenvolvimento da produção de Hariel nas interlocuções que englobam a decolonialidade e as perspectivas afro-indígenas, ou seja, em uma perspectiva interseccional e considerando suas interculturalidades. Para concluir, ao fazer uma articulação entre os estudos decoloniais e a produção da artista, seria no tocante ao seu enfrentamento, muitas vezes naturalizado, do racismo estrutural (ALMEIDA, 2018) no campo das artes. A artista, mesmo utilizando a categoria conceitual decolonial como marco teórico para suas pesquisas, consegue expressar uma análise crítica, neste aspecto. Hariel segue trilhando caminhos que se afinam às práticas artísticas insurgentes como possibilidade de visibilidade para corpos que historicamente foram silenciados e/ou invisibilizados socialmente, neste caso, as pessoas negras e indígenas como sujeitos - históricos na historiografia das artes visuais.

\section{CONSIDERAÇÕES FINAIS}

Atualmente, muitos museus estão criando maneiras de readaptações para uma experiência segura com a Arte. É importante frisamos e pensarmos nos museus como campos de disputa de uma nova realidade que demanda adaptações ao mundo cujo o futuro desconhecemos. A construção deste momento daqui para frente será coletiva, e isso significa abdicarmos de posturas conservadoras. Consiste não somente nesse olhar para o futuro incerto, mas num esforço de imaginação de mundos possíveis (KRENAK, 2019). Nesse sentido, nesse terreno de disputas a possibilidade da emergência de uma outra sociedade possível se faz urgente, na qual diversos grupos sociais possam atuar juntos de fato para construir novos valores e conhecimentos, ao invés de se pautarem pela transmissão de valores culturais baseados em desigualdades. Nesse campo, pensamos a curadoria, a prática artística e educativa como possibilidades de geração de novas formas, percepções e discursos. É preciso uma ação de difusão, com espaços de agenciamento coletivo, a partir da qual possamos reimaginar a potência de atuar em sociedade, algo que atualmente está tão fragilizado.

Estamos vivendo em um momento histórico de insurgência no que se refere aos novos artistas e curadores afro-diaspóricos comprometidos em compreender a 
produção artística e a prática curatorial e sua relação com o contexto contemporâneo. Onde encontra-se a produção afro-brasileira e seus sujeitos, superando o lugar de outro, a que sempre foram abordados por artistas brancos a partir de um olhar estereotipado. Transgredimos para o lugar de protagonismo da nossa própria história, apresentando novos temas, discussões, práticas, subjetividades e poéticas dos quais produzimos e protagonizamos. Essas questões são de extrema importância para o debate nas artes visuais como possibilidade para se pensar na construção de novas imagens, sendo essa uma estratégia poderosa de aquilombamento no campo das artes.

Acredito que no atual contexto da produção contemporânea, a produção de artistas afro-diaspóricos se insere como parte integrante de uma voz que sistematicamente é silenciada em circuitos hegemônicos. Mesmo havendo a historicidade do movimento negro brasileiro e a contribuição de intelectuais negros nos estudos sobre as relações étnico-raciais no Brasil, essa reflexão precisa ser ainda mais explorada também no campo das artes visuais na busca por outros tons para o debate afro-diaspórico na arte.

Longe de esgotar as reflexões neste texto, pois uma das facetas mais extraordinárias do campo de pesquisa nas artes está exatamente no oferecimento de possibilidades concretas para a visualização de elementos que compõem memórias e histórias que em sua maioria se encontram no campo das subjetividades. No caso da produção de Hariel, percebemos a possibilidade de articulação interdisciplinar entre o campo antropológico e as artes visuais, para a composição de uma narrativa histórica.

Podemos pensar a partir da produção de Hariel Revignet e de outros artistas afro-diaspóricos contemporâneos sobre uma renovação e historização da pintura que foge da forma, dos padrões e parâmetros da pintura tradicional. Os elementos incorporados nas obras de Hariel trazem muitas questões sociais e políticas que se configuram em contexto e discussão social atravessada pela natureza e sobre o reconhecimento e fortalecimento identitário de identidades diaspóricas originárias. Essas produções contemporâneas foram direcionadas aos temas voltadas para a construção de humanização, empoderamento e salvaguarda de uma memória e superação do racismo na sociedade brasileira.

Poderíamos ainda, a partir da escrita-vivência deste texto afirmar o quanto gostaríamos, enquanto artistas, pesquisadoras e curadoras negras, de reconhecer práticas transgressoras para descontruir lógicas hegemônicas no campo da arte e cultura. Almejamos que reconheçam e ativasas opressões e desigualdades. Pois é preciso muito mais do que repensar, mas que pudessem ter disponibilidade para construir diálogos com corpos diversos que produzam os aparelhos culturais como espaços públicos, onde será possível o reconhecimento e participação de diferentes agentes nas esferas culturais, de modo a alterar os jogos sociais desiguais. Muito mais do que produzir acessos, significa pensarmos na necessidade de rompermos a ideia que temos de produção de arte palatável ao cânone-branco-sistêmico, de rompermos as hierarquias entre os saberes, de descentralizarmos os meios e possibilidades de 
produzirmos e sermos reconhecidas, remuneradas e de escolher circularmos por diferentes instâncias institucionais e culturais produzindo novos modos de existências.

\section{Referências}

ALMEIDA, Silvio Luiz de. O que é racismo estrutural? Belo Horizonte (MG): Letramento, 2018.

ANAQUIRI, Mirna Kambeba Omágua-Yetê. Que memórias me atravessam? Meu percurso de estudante indígena. 2017. 151 f. Dissertação (Mestrado em Arte e Cultura Visual) Universidade Federal de Goiás, Goiânia, 2017.

BALLESTRIN, Luciana. América Latina e o giro decolonial. Rev. Bras. Ciênc. Polít. [online]. 2013, n.11, pp.89-117

BORGES, Rosane. Produção simbólica e diversidade da cultura afro-brasileira. São Paulo: Fundação Palmares, 2010

CHIARELLI, Tadeu. Territórios: artistas afrodescendentes no acervo da Pinacoteca. São Paulo: Pinacoteca do Estado de São Paulo, 2016 (Catálogo da Exposição)

COLLINS, Patricia Hill. Pensamento Feminista Negro: conhecimento, consciência e a política do empoderamento. Tradução Jamille Pinheiro Dias. $1^{a}$ edição. São Paulo: Boitempo Editorial, 2019. 495 p.

CONDURU, Roberto. Arte Afro-brasileira. Belo Horizonte: Editora C/Arte, 2007

CUNHA, Carneiro Mariano da. História Geral da Arte no Brasil. Volume II. São Paulo: Instituto Walther Moreira Salles. Fundação Djalma Guimarães, 1983

DUBOIS, W.E.B. As Almas da Gente Negra. Rio de Janeiro: Lacerda Editores, 1999.Dumará: Núcleo de Antropologia da Política, 1999. - (Coleção Antropologia da política)

ESBELL, Jaider. Tardes de agosto, manhãs de setembro, noites de outubro. Boa Vista: Edição do Autor, 2013.

EVARISTO. Conceição. A Escrevivência e seus subtextos. In DUARTE, Constância Lima; NUNES, Isabella Rosado (org.) Escrevivência: a escrita de nós: reflexões sobre a obra de Conceição Evaristo. Rio de Janeiro: Mina Comunicação e Arte, 2020, p. 26-46

FELINTO, Renata. A representação do negro nas artes plásticas brasileiras: diálogos e identidades. O Manelick $2^{\circ}$ Ato. São Paulo, 2013. Disponível em <http://www.omenelick2ato. com/artes-plasticas/dialogos-e-identidades>. Acesso em: 17 set. 2020 
FIGUEIREDO, Angela. Epistemologia insubmissa feminista negra decolonial. Tempo e Argumento, Florianópolis, v. 12, n. 29, e0102, jan./abr. 2020.

GILROY, Paul. O Atlântico negro: modernidade e dupla consciência. São Paulo: Editora 34, 2012.

GOMES, Nilma Lino. Educação, identidade negra e formação de professores/as: um olhar sobre o corpo negro e o cabelo crespo. Educação e pesquisa, v. 29, n. 1, p. 167-182, 2003.

GONZALEZ, Lélia. A categoria político-cultural de amefricanidade. Revista Tempo Brasileiro, Rio de Janeiro, v. 92, n. 93, p. 69-82, 1988.

GONZALEZ, Lélia. A Mulher Negra na Sociedade Brasileira (Uma abordagem políticoeconômica). In: MADEL, Luz. (org.). O lugar da Mulher (Estudos sobre a condição feminina na sociedade atual). Rio de Janeiro: Graal, 1982

GUAJAJARA, Sônia. Sônia Guajajara. Organização de Sérgio Cohn e Idjahure Kadiwel. Rio de Janeiro: Azougue Editorial, 2018 (Coleção Tembetá).

HOOKS, bell. Ensinando a transgredir: a educação como pratica da liberdade. São Paulo: Editora Martins Fontes, 2013.

HOOKS, bell. Vivendo de Amor. Disponível em: <https://www.geledes.org.br/vivendo-deamor/>. Acesso em 16 de fev 2021

HOOKS, bell. Olhares Negros, Raça e Representação. Editora Elefante. 2019.

KILOMBA, Grada. Memórias da plantação - Episódios de racismo cotidiano. Trad. Jess Oliveira. Rio de Janeiro: Cobogó, 2019.

KOPENAWA, Davi; ALBERT, Bruce. A queda do céu: palavras de um xamã yanomami. São Paulo: Companhia das Letras, 2015.

KRENAK, Ailton. Encontros. Organização de Sérgio Cohn. Rio de Janeiro: Azougue Editorial, 2015.

KRENAK, Ailton. Ideias para adiar o fim do mundo. São Paulo: Companhia das Letras, 2019.

MUNANGA, Kabengele. Rediscutindo a mestiçagem no Brasil: identidade nacional versus identidade negra. Petrópolis, RJ: Vozes, 1999.

MUNDURUKU, Daniel. Memórias de índio: uma quase autobiografia. Porto Alegre: EDELBRA, 2016.

MUNDURUKU, Daniel. O caráter educativo do movimento indígena brasileiro (1970-1980). São Paulo: Paulinas, 2012.

NASCIMENTO, Maria Beatriz (1985) O conceito de quilombo e a resistência cultural negra. Afrodiáspora Nos. 6-7, pp. 41-49

POTIGUARA, Eliane. Metade cara, metade máscara. Lorena: DM Projetos Especiais, 2018. 
QUIJANO, Aníbal. Colonialidade do poder, Eurocentrismo e América Latina. CLACSO, Consejo Latino americano de Ciencias Sociales, Buenos Aires. 2005. Disponível em: <http:// bibliotecavirtual.clacso.org.ar/clacso/sur-sur/20100624103322/12_Quijano.pdf acesso> em: 20 fev. 2021.

REVIGNET. Hariel C. O. Expor Agombenero Ancestrais. Goiânia. 18 dez. 2018. Instagram:@ harielrevignet. Disponível em <https://www.instagram.com/p/BrddwLAnDug/>. Acesso em: 20 jan. 2021

REVIGNET. Hariel C. O. Axétetura: espaços do sagrado à margem; Perspectiva decolonial para estudo de caso autobiogeográfico do terreiro de umbanda Casa de Caridade Luz do Alvorecer. Trabalho de Conclusão de Curso. Graduação em Arquitetura e Urbanismo. Universidade Federal de Goiás - UFG. Goiânia/GO. 2019

REVIGNET, Hariel C. O. AMARRAÇÃO. Goiânia. 20 nov. 2020a. Instagram:@kuraarte. Disponível em < https://www.instagram.com/tv/CHOqn7CHU73/?utm_source=ig_web_copy_ link\%3E>. Acesso em: 20 jan. 2021

REVIGNET, Hariel C. O. A tradição da pintura. KURA ENTREVISTA / NACIONAL TROVOA. Site Kuraarte. 2020b. Disponível em: < http://www.kuraarte.com.br/blog/entrevista-trovoa/>. Acesso em: 20 jan. 2021

REVIGNET, Hariel C. O. Reivindicando uma herança escolhida. Ocupação Solar dos Abacaxis: projeto NTÚ. 13 fev. 2021. Instagram:@solardosabacaxis. Disponível em < https:// www.instagram.com/p/CLPunBRJ3AD/ > Acesso em: 13 fev. 2021

RODRIGUES, Manoela. Autobiogeografia como metodologia decolonial. 2017. Disponível em: <https://www.researchgate.net/publication/320212758>. Acesso em: 20 fev. 2021.

SANTOS. Renata A.F. Mesa saberes e práticas artísticas decoloniais. In PAIVA, Alessandra Mello Simões (org.) Anais da LXI Jornada da Associação Brasileira de Críticos de Arte, Itabuna, BA, 25 a 27 de nov. de 2020 [recurso eletrônico]: resistências poéticas: arte, crítica e direitos humanos. - Itabuna: UFSB, 2020. 211p.

SIMÕES, Igor Moraes. Fragmentos para uma história insubmissa da arte no Brasil: história da arte, epistemologias outras e visibilidades negras, In Anais do 27o Encontro da Associação Nacional de Pesquisadores em Artes Plásticas, 27o, 2018, São Paulo. Anais do 27o Encontro da Anpap. São Paulo: Universidade Estadual Paulista (UNESP), Instituto de Artes, 2018. p.2463-2474.

SIMÕES, Igor Moraes. Montagem Fílmica e Exposição: Vozes Negras no Cubo Branco da Arte Brasileira / Igor Moraes Simões.2019. 298 f. Tese (Doutorado) -- Universidade Federal do Rio Grande do Sul, Instituto de Artes, Programa de Pós-Graduação em Artes Visuais, Porto Alegre, BR-RS, 2019.

Submissão: $19 / 02 / 21$

Aceitação: 10/04/21 